\title{
Exacerbation of experimental pyelonephritis by cyclosporin A
}

\author{
T. E. MILLER and GLENNE FINDON
}

\section{Department of Medicine, Auckland Hospital, Park Road, Auckland, New Zealand}

\begin{abstract}
Summary. An athymic rat strain lacking functional $\mathrm{T}$ cells was used to assess the role of cell-mediated immunity (CMI) in host defence against renal infection. CMI was ruled out as a relevant host defence component, but when cyclosporin A (CsA) was administered to athymic animals, renal infection was exacerbated. CsA is thought to affect $\mathrm{T}$ lymphocyte function and, in the absence of a target cell, cellular defences in the athymic animal were not expected to be compromised by CsA. An effect on noncellular defence mechanisms was therefore considered but our studies did not support this explanation--rather they indicated a depression of either cellular defences or of a specific cellular component. The present experiments have provided additional information on the relationship between CsA administration and the depression of host defence mechanisms but further studies will be necessary to identify the components affected.
\end{abstract}

\section{Introduction}

The fungal oligopeptide cyclosporin A (CsA) is being used with increasing frequency to prevent organ graft rejection. The clinical effectiveness of CsA can be explained by its ability to prevent the release of T-cell-associated lymphokines that promote cell-mediated responses (Bunjes et al., 1981; Kahan, 1985). CsA has significantly greater target specificity than other immunosuppressive drugs as it affects only T lymphocyte sub-types (Hess et al., 1986). It does not interfere with neutrophil function (Janco and English, 1983) and should therefore not affect host defences to extracellular pathogens. Several reports have appeared describing the effect of CsA on host resistance to experimentally induced cryptococcal meningitis (Perfect and Durack, 1985), listeriosis (Schaffner et al., 1983), faecal peritonitis (Moffat et al., 1985) and lymphocytic choriomeningitis virus infection (Loliger and Lehmann-Grube, 1985). While some of the observations reported could be explained by an effect on $\mathrm{T}$ lymphocytes and cell-mediated immunity (CMI), others clearly cannot.

We have shown that CsA exacerbates experimentally induced renal infection without affecting circulating leucocyte numbers (Miller and Findon, 1986). The dose of CsA used was considered to be a clinically equivalent dose (Thomson et al., 1981).

Received 7 May 1987; revised version accepted 7 Oct. 1987.
These observations were of particular interest as we had previously shown that bacterial numbers in the kidneys of animals with experimentally induced renal infection increased only after circulating and recruitable neutrophils had been grossly depleted (Miller et al., 1986). Therefore the conditions under which CsA provoked renal infection appeared to be markedly different from those associated with cyclophosphamide administration. In the present experiments we set out to identify the host defence mechanisms(s) affected by CsA with a view to explaining the exacerbation of experimentally induced renal infection by this agent.

\section{Materials and methods}

\section{Experimental host}

Adult Dark Agouti (DA) rats from an inbred colony, weighing $180-250 \mathrm{~g}$, were used in the majority of these experiments. In specified cases, homozygous athymic nude mutant rats $\left(\mathrm{rnu}^{\mathrm{nz}} / \mathrm{rnu}^{\mathrm{nz}}\right)$ were also used. These animals have a non-functional thymic anlage and lack $T$ cell function (Douglas-Jones et al., 1981; Marshall and Miller, 1981). The euthymic (heterozygous) parent strains were used as controls.

\section{Cyclosporin A administration}

CsA (Sandimmun, Sandoz Ltd, Basle, Switzerland) was administered on alternate days into the thigh muscle of lightly anaesthetised rats. Doses of $3,6,12 \cdot 5,25$ or 
$50 \mathrm{mg} / \mathrm{kg}$ were given in a volume of $100 \mu \mathrm{l}$. Preliminary experiments had shown that it was necessary to give CsA over a period of 7 days before challenge and throughout the course of the experiment, in order to depress host defences. The CsA solubilising agent, Cremaphor EL (BASF Aktiengesellschaft, D-6700, Ludwigshafen, West Germany), was given to control animals.

\section{Cyclophosphamide administration}

A slow release method, utilising surgical bone cement as a polymeric carrier, was used to administer cyclophosphamide. The technique has previously been described in detail (Ormrod et al., 1985). Varying numbers of subcutaneously implanted bone cement disks, each containing cyclophosphamide (Endoxan-Asta, AstaWerke AG, Bielefeld, West Germany) $75 \mathrm{mg}$, were implanted into animals to achieve graded cytodepletion. Doses used were $75,150,225,300$ and $375 \mathrm{mg}$ and the disks were implanted 6 days before challenge. Drug-free disks were implanted in control animals.

\section{Effect of CMI on acute pyelonephritis}

Experiments with athymic rats were carried out to ascertain the effect of CMI on experimental renal infection. Firstly, three groups of four athymic animals were assayed 7,14 , and 28 days after challenge and compared with the euthymic strain from which they were derived. In another experiment two groups of six athymic animals were used. One group was treated with CsA $50 \mathrm{mg} / \mathrm{kg}$ and the remaining six were used as controls. Pyelonephritis was induced 7 days after the commencement of CsA treatment and animals were killed 3 days after challenge.

\section{Experimental infections}

Each infection was assayed separately in groups of 12 rats, except for lung infection, for which 16 animals were used. Preliminary experiments were performed to ascertain the time course for each infection. The time chosen for quantitative evaluation was when bacterial numbers had stabilised.

Pyelonephritis. This was induced by the introduction of Escherichia coli strain 075 into the kidney, through a glass microcapillary pipette (Miller and Robinson, 1973). Two 5- $\mu$ l volumes of inocula, each containing $c .1500 \mathrm{cfu}$, were injected directly into the surgically exposed kidney.

Subcutaneous infection. Cylindrical sponges $(2.5 \times 1 \mathrm{~cm}$, $40 \pm 1 \mathrm{mg}$ ) were cut from polyurethane absorbent foam packing (ICI Tasman Ltd, Upper Hutt, New Zealand) and sterilised by autoclaving at $121^{\circ} \mathrm{C}$ for $15 \mathrm{~min}$. An incision was made at each side of the dorsal midline, the fascia retracted by blunt dissection and a sponge was implanted in each subcutaneous space. Care was taken to observe strict aseptic technique at all times. Once in place, each sponge was infected with $50 \mu$ of $E$. coli $\mathrm{O} 75$ containing $10^{4} \mathrm{cfu}$ and the incision was then closed.
Yeast cell infection of the footpad. Candida albicans, $10^{6}$ cells in $20 \mu \mathrm{l}$ of saline (Miller and Findon, 1985), was injected intradermally into the plantar tissue of the hind footpads.

Respiratory infection. A small midline cervical incision was made, and the trachea was exposed. A curved 18gauge needle was inserted into the trachea through which an $8 \mathrm{~cm}$ plastic cannula was passed into the base of the lung. The inoculum, containing Klebsiella pneumoniae $10^{8} \mathrm{cfu}$ in $100 \mu \mathrm{l}$ of saline, was then introduced into the lung through the cannula. The incision was closed with a running suture.

\section{Estimation of bacterial numbers in the host tissue}

Kidney. Kidneys were removed aseptically 7 days after challenge and homogenised in $9 \mathrm{ml}$ of saline with a rotating teflon pestle in a heavy walled glass tube. Tenfold dilutions of the homogenate were then added to Columbia agar pour plates to estimate the bacterial content of each kidney.

Footpad. Ten days after challenge, the footpads were removed aseptically, chopped coarsely and homogenised in $9 \mathrm{ml}$ of saline. The number of viable yeast cells $/ \mathrm{g}$ of footpad was determined in ten-fold dilutions on Sabouraud Dextrose Agar (Difco Laboratories, Detroit, MI, USA) pour plates containing chloramphenicol $0 \cdot 1 \mathrm{mg} / \mathrm{ml}$ (Chloromycetin; Parke-Davis and Co. Ltd, USA).

Sponges. Sponges were removed $72 \mathrm{~h}$ after implantation, with strict aseptic technique. Micro-organisms were squeezed from each sponge into $9 \mathrm{ml}$ of saline by use of a rotating teflon pestle in a heavy walled glass tube. Columbia-agar pour plates were then prepared from tenfold dilutions and the bacterial count/sponge obtained.

Lung. The main thoracic blood vessels were clamped off and the lungs removed $72 \mathrm{~h}$ after infection. They were weighed, chopped coarsely with scissors and homogenised. Columbia-agar pour plates, as described above, were used to determine the bacterial count/g of lung tissue.

\section{Neutrophil recruitment}

Neutrophil recruitment was selected as the assay to quantify host defence status. The selection was based on pilot experiments which had shown that a decrease in this function is associated with an increase in bacterial numbers in the kidney. Subcutaneously implanted sponges were used to harvest mobilising neutrophils from the animal hosts. The cells were squeezed from the sponge and counted in a haemocytometer. A differential count was carried out on a Leishman-stained cell smear, prepared in a cytospin centrifuge (Miller et al., 1986).

\section{Statistical analysis}

Results were evaluated by the non-parametric Wilcoxon sum of ranks test. 


\section{Results}

Relationship between recruitable neutrophil numbers and the bacteriological status of the kidneys in experimentally induced E. coli pyelonephritis

Studies were performed to provide quantitative information on the effects of host depletion of recruitable neutrophils by CsA and cyclophosphamide. Increasing the dose of cyclophosphamide resulted in a progressive loss of recruitable neutrophils when compared with the normal control group $(100 \%)$ (vertical axis, fig. 1). Bacterial numbers in the kidney (horizontal axis, fig. 1) increased only when recruitable neutrophils were grossly depleted. Increasing amounts of CsA also led to an increase in renal bacterial numbers, but in this case, significant changes to the bacteriological status of the kidneys occurred at a stage when neutrophil recruitment was relatively unimpaired.

\section{Cell-mediated immune mechanisms in pyelonephritis}

CsA affects T-lymphocyte physiology, and it

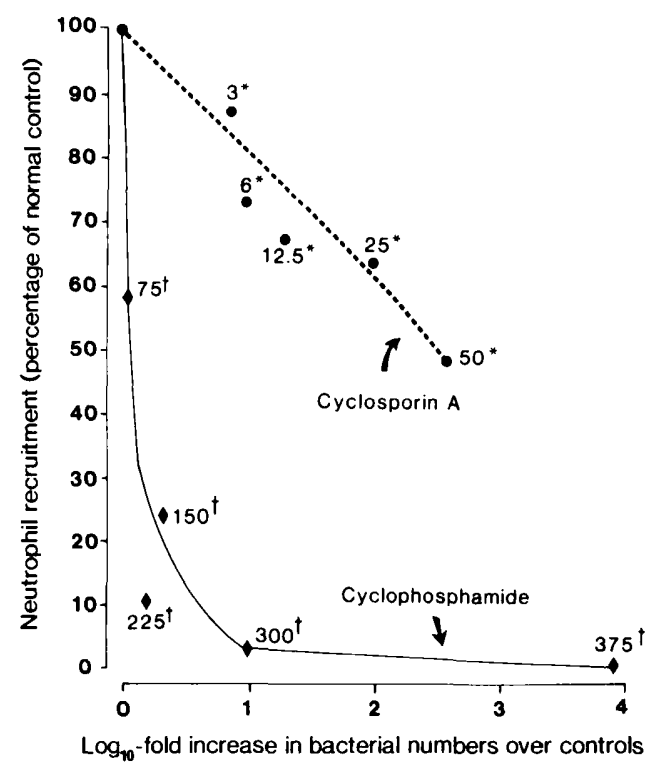

Fig. 1. Effects of cyclophosphamide and cyclosporin A on the bacteriological status of the kidney in experimentally induced renal infection. Increasing amounts of cyclophosphamide (75$375 \mathrm{mg}$ in polymeric implants $\dagger)$ or cyclosporin A $(3-50 \mathrm{mg} / \mathrm{kg}$, intramuscularly*) were administered to groups of six animals to deplete progressively the cellular defence. Neutrophil recruitment (vertical axis) was used to indicate the percentage of cellular responsiveness remaining after the different amounts of cyclosporin $\mathbf{A}$ and cyclophosphamide had been administered. The horizontal axis indicates the corresponding effect of these manipulations on the bacteriological status of the kidney. Results from the control group were used to plot $100 \%$ neutrophil recruitment and 0 -fold increase in bacterial numbers. could be argued that an assay of T-cell function would have been more appropriate than neutrophil recruitment as a measure of cellular competence. The role of $T$ cells as a host defence mechanism in renal infection was therefore evaluated in the athymic mutant rat. We found that the absence of host $\mathrm{T}$ cells had no effect on the bacteriological status of the kidney over the 28-day period studied (fig. 2); this suggests that $C M I$ is not a critical host defence determinant in pyelonephritis.

\section{Effect of CsA on non- $T$ cell defence mechanisms}

CsA was administered to animals from the athymic rat strain to determine the effect of this agent on defences in a T-cell-depleted host. The level of infection was markedly enhanced and the mean renal bacterial numbers in CsA-treated athymic animals were 100 times greater than in untreated animals (fig. 3). The experiment demonstrated an effect of CsA on defence mechanisms in a host lacking a target cell for this agent and suggests that a non-T cell host defence component was affected.

\section{Does CsA affect a cellular or non-cellular defence mechanism?}

One interpretation of the previous result was that CsA affected non-cellular factors in the kidney associated with host defences. An effect on renal blood flow would be an example (Murray et al., 1985). If this was the explanation for the current findings, the ability of CsA to promote infection would be limited to renal infection. The question was answered by comparing the effects of CsA on

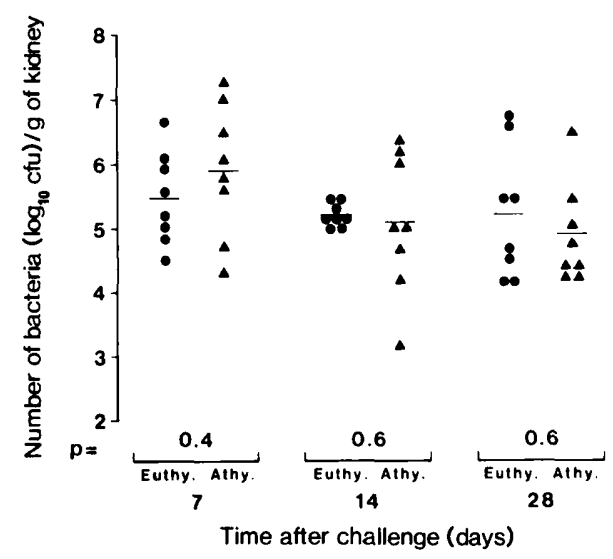

Fig. 2. Effect of $T$ cell ablation on the bacteriological status of the kidney in experimentally induced pyelonephritis. A comparison of athymic (nude) hosts and heterozygous (euthymic) controls. Horizontal bars represent means of observed values. 


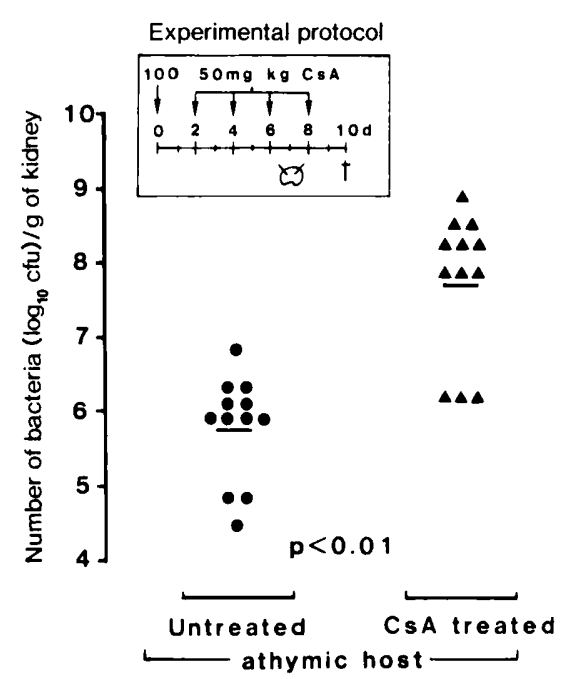

Fig. 3. Bacteriological status of the kidney in athymic (nude) hosts treated with cyclosporin A $50 \mathrm{mg} / \mathrm{kg}$, according to the protocol shown. Horizontal bars represent means of observed values.

renal and other local infections. Cellular defences were progressively depleted by administering increasing amounts of CsA. Neutrophil recruitment into subcutaneously implanted sponges was used to quantitate the degree of depletion. Infection of the kidney, subcutaneous tissue, footpads and lungs were all exacerbated as the dose of CsA was increased (fig. 4). This finding suggests an effect of CsA on cellular defence components rather than a specific effect on host defence elements in the kidney. Cytodepletion was also done with cyclophosphamide to confirm that there were no inherent differences in the cellular defence requirements for the individual infections that might account for the results obtained with CsA.

\section{Discussion}

In a recent report (Miller and Findon, 1986), evidence was presented that cyclosporin A exacerbated experimentally induced $E$. coli renal infection at clinically equivalent doses of the drug. This was an unexpected result and we initiated studies to resolve this apparently anomalous finding. Two quite different relationships were found when the association between cellular defences and severity of infection in CsA- or cyclophosphamide-treated animals were compared by quantitative parameters. Bacterial numbers in the kidneys of CsA treated animals increased markedly, although cellular defence mechanisms were only moderately

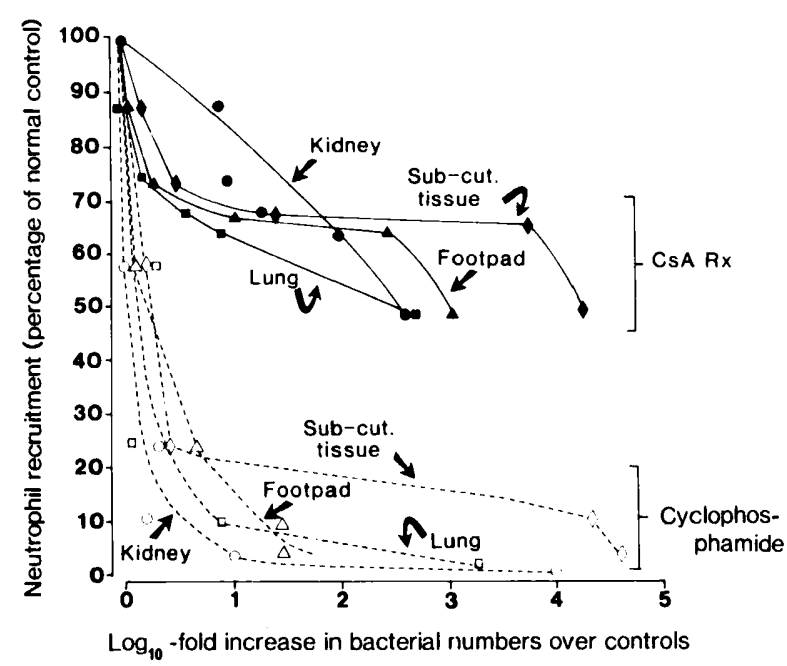

Fig. 4. Effect of increasing doses $(L \rightarrow R)$ of cyclosporin $A$ (3$50 \mathrm{mg} / \mathrm{kg}$, i.m.) or cyclophosphamide $(75-375 \mathrm{mg}$ in polymeric implants) on cellular defence mechanisms (neutrophil recruitment, vertical axis) and the bacteriological course of experimentally induced infections (horizontal axis). Each point is the mean result of evaluating neutrophil recruitment and bacteriological status of 6-8 animals. The control group represents $100 \%$ neutrophil recruitment and 0 -fold increase in bacterial numbers.

depressed. This finding contrasted with the ablation of cellular competence with cyclophosphamide that was needed to achieve an equivalent increase in bacterial numbers in the kidneys. In these experiments, neutrophil recruitment was used to quantify cellular defence mechanisms on the basis that a decrease in this function had been previously associated with an increase in bacterial numbers in the kidney (Miller et al., 1986). The target cell for CsA however is a $T$ cell subset, so neutrophil mobilisation would not have been an appropriate measure of cellular competence if $\mathrm{T}$ lymphocytes were shown to be involved in host defences to renal infection. However, when the role of CMI in cellular defences was assessed, it proved to be an unimportant determinant of the bacteriological status of the kidney. Therefore we were satisfied that neutrophil mobilisation was an appropriate test of cellular competence in the CsA-treated group. We next investigated whether the effect of CsA on host defences might lie outside the cellmediated immune system. Availability of an athymic host allowed this hypothesis to be investigated, as the mutant lacks functional $\mathrm{T}$ cells and, in the absence of a target cell, the cellular defences of such a host should not be compromised further by the administration of CsA. However, host defences against pyelonephritis were depressed in 
athymic animals treated with $\mathrm{CsA}$ and a marked provocation of renal infection was observed. CsA is known to affect renal blood flow (Murray et al., 1985) and interference with humoral components of the immune and inflammatory systems could explain these findings if it could be demonstrated that exacerbation of infection by CsA was limited to renal tissue. Therefore, the effect of CsA on renal and other local infections was compared. The protocol was based on the hypothesis that if noncellular defences in the kidney were affected by CsA, the changes observed would be limited to renal infection but if a cellular mechanism was involved then other local infections would also be affected. We found that CsA administration also provoked $E$. coli-induced subcutaneous infection, $C$. albicans infection of the footpad and $K$. pneumoniae respiratory infection. This result ruled out the possibility that CsA affected non-cellular defence mechanisms in the kidney and raised the question of a wider effect of CsA on cellular defences.

The observation that CsA exacerbated renal infection even though circulating and recruitable neutrophil numbers were relatively unaffected (compared with the results with cyclophosphamide) suggests that cellular defences other than neutrophil leucocytes were depressed by CsA. Depression of
CMI by CsA was ruled out as a possible factor after it was shown that the course of infection was not altered by the total absence of $T$ cells in the athymic host. Depression of cellular defences or a specific cellular defence other than CMI, seems to be the most likely explanation for these observations.

The present experiments have therefore provided a considerable amount of additional information on the relationship between CsA administration and the depression of host defence mechanisms. A number of possibilities have been investigated but, at this stage, further studies are needed to provide a clear explanation for the exacerbation of local infections by CsA. These include the possibility that CsA induces a qualitative change in neutrophil function rather than a quantitative change in recruitment response. Furthermore, the clinical significance of our findings needs to be determined, but they may help to explain the current pattern of infectious disease associated with CsA treatment including unexpected episodes of infection in individual patients (Najarian et al., 1983; Oyer et al., 1983; Sells, 1983; Shiel et al., 1983).

This study was supported by the Medical Research Council of New Zealand. We also thank Mrs Elsie Chapman for typing the manuscript.

\section{REFERENCES}

Bunjes D, Hardt C, Röllinghoff M, Wagner H 1981 Cyclosporin A mediates immunosuppression of primary cytotoxic $T$ cell responses by impairing the release of interleukin 1 and interleukin 2. European Journal of Immunology 11:657-661.

Douglas-Jones A, Nelson J, Jansen V, Miller T 1981 Characterization of the $\left(\mathrm{rnu}^{\mathrm{nz}}\right)$ nude rat. Morphological characteristics of the lymphoid system. Australian Journal of Experimental Biology and Medical Science 59 : 277-286.

Hess A D, Colombani P M, Esa A H 1986 Cyclosporine and the immune response: basic aspects. CRC Critical Reviews in Immunology 6: 123-149.

Janco R L, English D 1983 Cyclosporine and human neutrophil function. Transplantation 35:501-503.

Kahan B D 1985 Cyclosporine: the agent and its actions. Transplantation Proceedings 17 (Suppl 1): 5-18.

Loliger C, Lehmann-Grube F 1985 Mechanism of recovery from acute virus infection. II. Effect of treatment of mice with cyclosporin A on their ability to eliminate the lymphocytic choriomeningitis virus. Medical Microbiology and Immunology 174 : 187-196.

Marshall E, Miller T 1981 Characterization of the nude rat $\left(\mathrm{rnu}^{\mathrm{nz}}\right)$. Functional characteristics. Australian Journal of Experimental Biology and Medical Science 59 : 287-296.

Miller T E, Findon G 1985 Experimental candidosis: paw oedema in the analysis of a local infection. Journal of Medical Microbiology 20:283-290.

Miller T E, Findon G 1986 Modulation of host defenses against pyogenic microorganisms by cyclosporine. Transplantation 42: 463-466.

Miller T E, Findon G, Cawley S, Clarke I 1986 Cellular basis of host defence in pyelonephritis. II. Acute infection. British Journal of Experimental Pathology 67:191-200.

Miller T E, Robinson K B 1973 Experimental pyelonephritis : a new method for inducing pyelonephritis in the rat. Journal of Infectious Diseases 127:307-310.

Moffat F L et al. 1985 Reversal of cyclosporine-induced mortality with a synthetic polymeric immunostimulant in a murine model of fecal peritonitis. Transplantation 39:369-374.

Murray B M, Paller M S, Ferris T F 1985 Effect of cyclosporine administration on renal hemodynamics in conscious rats. Kidney International 28:767-774.

Najarian J S et al. 1983 Comparison of cyclosporine versus azathioprine-antilymphocyte globulin in renal transplantation. Transplantation Proceedings 15:2463-2468.

Ormrod D J, Cawley S, Miller T E 1985 Extended immunosuppression with cyclophosphamide using controlled-release polymeric implants. International Journal of Immunopharmacology 7:443-448.

Oyer P E et al. 1983 Cyclosporine in cardiac transplantation: a $2 \frac{1}{2}$ year follow-up. Transplantation Proceedings 15:25462552.

Perfect J R, Durack D T 1985 Effects of cyclosporine in experimental cryptococcal meningitis. Infection and Immunity 50:22-26.

Schaffner A, Douglas H, Davis C E 1983 Models of T cell 
deficiency in listeriosis: the effects of cortisone and cyclosporin A on normal and nude BALB/c mice. Journal of Immunology 131 : 450-453.

Sells R A 1983 A prospective randomized substitutive trial of cyclosporine as a prophylactic agent in human renal transplant rejection. Transplantation Proceedings 15: 24952500 .
Shiel A G R et al. 1983 Australian trial of cyclosporine (CsA) in cadaveric donor renal transplantation. Transplantation Proceedings 15:2485-2489.

Thomson A W, Whiting P H, Cameron I D, Lessels S E, Simpson J G 1981 A toxicological study in rats receiving immunotherapeutic doses of cyclosporin A. Transplantation $31: 121-124$. 